\title{
Assessing the Stakeholders' Contribution to Business Value
}

\author{
Elena Patrusheva, Elena Sapir, and Igor Karachev* \\ P.G. Demidov Yaroslavl State University, Sovetskaya Str., 14, 150003 Yaroslavl, Russia
}

\begin{abstract}
Stakeholder theory is the most attractive fundamental concept to ensure the necessary improvement of corporate governance in the modern world, integrated into the idea of value maximization as the main strategic goal of the enterprise. The proposed concept of total value considers this category as the sum of the organizational wealth and the values of the stakeholders, which together constitute the total contribution of the economic system to public welfare. Recognizing not only the financial implications of stakeholder relationships, the authors propose practical tools for value management, based on the agreed interaction of stakeholders - the modeling of resource flows to optimize the resulting total value and the algorithm of step-by-step management of interaction with stakeholders. The modeling of value creation reflects both the organizational benefits of interaction and explicitly identifies the value of the stakeholders' benefits, and also discloses a list of key management factors: the economic value of the resources used by parties, the fairness of the exchange, the relationship between interacting companies, the opportunity costs, etc. Critical aspects of value creation that go beyond profitability and economic returns are highlighted. Corporate values can only be understood by reference to the multiplicity of stakeholders' value perspectives.It is recommended that the process of managing interaction with stakeholders should be guided by an extensive interpretation of the target (value) setting of the business, taking into account the totality of material and intangible resource flows between the parties.
\end{abstract}

\section{Introduction}

As a strategic goal, most modern companies have adopted a focus on business value growth. The achievement of this goal within the framework of the Value Based Management (VBM) concept has traditionally been carried out mainly through the owners' welfare growth.

The crisis currently unfolding in the world economy shows that the previous model of corporate governance, which is oriented towards the interests of individual groups of owners and is highly related to unstable capital markets, needs significant adjustments necessary to ensure more stable economic growth in the long term.

For decades, value creation was understood as maximizing equity value, with a focus on outcomes rather than processes or intentions. Stakeholder Behavioral Theory focuses on the

*Corresponding author: karachev2011@yandex.ru 
issue of «overlapping value» and, in particular, why stakeholders come together voluntarily to cooperate within the company [1-2].The purpose of identifying the overlapping value of stakeholders implies that the value derived by stakeholders from relationships or networks (e.g., supply chains) will affect whether they participate in transactions. When members of a network find overlapping points of value, they are interested in coming together and cooperating.

R.E. Freeman [2] argued that the success of an organization is determined by the degree of satisfaction of the stakeholders, which include shareholders, top managers and employees, consumers and suppliers, public authorities, as well as other interacting groups. Stakeholder theory considers any organization to be a network of interrelated elements, each of which contributes (voluntarily or compulsorily) to the results of the organization's activities and expects to benefit (or to avoid non-compensable harm) [3]. J.E. Post, L.E. Preston and S. Sachs emphasized the expediency of changing traditional views on the nature of the organization in the context of the rapid development of business networks, information services, and the knowledge economy [4].

Subsequently, in this theory, it was the increase in the value of the company that established itself as a criterion for strategic development [5]. The stakeholder theory formulated by M.C Jensen, which produced a measure of efficiency, became called enlightened stakeholder theory [6].

Value management requires the specification of the processes of interaction with the stakeholders and, in particular, the measurement of the financial contribution to its establishment by the various stakeholder groups, as well as the social impact of stakeholder interaction, to manage value maximization by understanding it as an integral value, the individual components of which are created in contact with one or another group of stakeholders.

The general hypothesis of the study is that effective interaction of an organization with its stakeholders leads to the excess of benefits over costs and the creation of positive net cash flows, which are the basis of the firm's sustained growth in value.

\section{Methods}

The methodology for estimating the value of an enterprise's relationships with individual stakeholders is based on model F. Figge, which determines the value as follows [7]:

$$
S t V=\sum_{n=1}^{N} \frac{R_{n}-C_{n}}{(1-d)^{n}}
$$

Where StV -value created by the stakeholder; $\mathbf{R}_{\mathbf{n}}-$ revenue from interaction with the stakeholder; $\mathbf{C}_{\mathbf{n}}$ - stakeholder maintenance costs; $\mathbf{d}$ - discount rate; $\mathbf{N}$ - duration of the forecast period.

However, F. Figge [7] is of the view that the only party with which an enterprise has reciprocal cash flows is shareholders and creditors, while the direct cash flows of other stakeholders are only one-sided (for example, staff, government and suppliers are characterized by cash outflows from the enterprise in the form of wages, taxes, payment for raw materials, respectively).This position is somewhat limited. A number of modern researchers criticize the idea of creating only financial value for «arbitrary reduction of the potential range of factors» [8], arguing that «striving for financial success is necessary in such a way as to also bring social benefits» [9].

We believe that the relationship between the company and each group of its stakeholders is bilateral in nature and is expressed in cash flows, both received and spent. 
On the one hand, it is clear that if an enterprise's value consists of the benefits it derives from its stakeholders, stakeholders are, in aggregate, the resource that makes the greatest contribution to the organization's wealth. On the other hand, stakeholders decide to engage with the enterprise only on the basis of the value of the benefits it generates, i.e., considering it as their resource. Adopting a resource-based approach to the organization's relationship vision and its stakeholders through cash flows requires a model description that removes the limitations of F. Figge's views.

This is the case with the concept of total value (CTV) of an enterprise, since it is not only intended to describe the individual elements of value arising from the relationship between the enterprise and its stakeholders, but also to show the natural relationships between them, as well as integrating parts into a coherent whole.

The overlapping value for stakeholders in networks reflects the converging interests of all participants in creating value, which includes economic considerations, as well as equity, trust and a sense of that the firm and its operations will allow all stakeholders to become more successful over time. Value created to one stakeholder depends on the behavior of other stakeholders in the firm.

Another important aspect of this idea, not found in the literature studied, is the solution to the multi-tasking problem of governance noted by $\mathrm{M}$. Jensen, which implies the impossibility of maximizing in several directions. On the face of it, the presence, in addition to the organizational wealth, of the value of stakeholders whose interests must be taken into account poses a challenge to managers in identifying and setting priorities, as stakeholders may demand simultaneous, equivalent, different and continuous attention [1011].

The conceptual approach, based on the identification of overlapping benefits in networks with stakeholders, assumes that different parties have a positive correlation between the economic value and the benefits of continuous cooperation. Where this is not the case, opportunism threatens the relationships among network members, especially where initiatives to ensure the sustainability of the network are costly and time-consuming.

One of the few (albeit substantial) weaknesses of our idea is that its understanding of the processes of creation and distribution of values is not yet sufficiently widespread in practice, which in turn leads to a lack of methodological approaches necessary for the realization of the stated ideas in management activities. Therefore, the next necessary step is to give the CTVan economic content and to identify, on that basis, the fundamental principles on which the enterprise value management in the context of the stakeholder theory should be built.

\section{Results}

The resource approach to value means that transaction participants continuously measure the benefits and costs of doing the transactions. They seek to maximize their income in order to cover their resources and efforts.For the exchange to be a non-zero-sum game, parties must increase transaction volumes before the available resources are exhausted.

In the case of diminishing marginal utility of resource flows, the parties will increase the exchange until the marginal income of one of them equals the marginal cost. It can therefore be concluded that maximizing the value of a company will involve maximizing the value of its stakeholders simultaneously, which together results in maximizing the contribution of the economic system to public welfare:

$$
\begin{aligned}
& f_{0}\left(x_{0}\right) \rightarrow \max \Leftrightarrow f_{i}\left(x_{i}\right) \rightarrow \max , \\
& D\left(x_{0}, x_{i}\right):\left\{0 \leq x_{0} \leq X_{0}, 0 \leq x_{i} \leq X_{i}, i \in 1: M\right\}
\end{aligned}
$$


where $\mathbf{f}_{\mathbf{0}}\left(\mathbf{x}_{\mathbf{0}}\right)$ and $\mathbf{f}_{\mathbf{i}}\left(\mathbf{x}_{\mathbf{i}}\right)$ - target functions of the enterprise and stakeholders; $\mathbf{X}_{\mathbf{0}}$ and $\mathbf{X}_{\mathbf{i}}-$ size of the enterprise's and stakeholder's stock of resources; $\mathbf{M}$ - number of the enterprise's stakeholders.

The application aspect of the CTV involves the identification of mechanisms for the creation and estimation of certain types of value.

We believe that the value of the company $\left(\mathbf{V}_{\mathbf{i}}\right)$ created through contacts with one or another stakeholder can be expressed as follows:

$$
V_{i}=\sum_{n=1}^{N} \frac{R_{i n}-C_{i n}}{\left(1+d_{0}\right)^{n}}=\sum_{n=1}^{N} \frac{\sum_{k=1}^{K} \bar{X}_{i k} r_{0 k}-\sum_{l=1}^{L} \vec{X}_{i l} p_{0 l}}{\left(1+d_{0}\right)^{n}}
$$

where $\mathbf{R}_{\text {in }}$ - value of the resources received; $\mathbf{C}_{\text {in }}$ - value of the resources transferred; $\mathbf{d}_{\mathbf{0}}$ - discount rate; $\mathbf{N}$ - duration of the forecast period; $\overline{\boldsymbol{X}}_{\boldsymbol{i} \boldsymbol{k}}$ - natural volume of the resource $\mathrm{k}$ received by the enterprise; $\mathbf{r}_{\mathbf{0}}$ - value (profitability) of using resource $\mathrm{k}$ by the enterprise; $\vec{X}_{i l}$ - natural volume of the resource 1 transferred by the enterprise; $\mathbf{p}_{01}$ - value (price) of the resource 1 for the enterprise; $\mathbf{K}, \mathbf{L}$ - number of names received and transferred resources respectively.

The same logic can be applied to the stakeholder value $\left(\mathbf{S t V}_{\mathbf{i}}\right)$ created by the company:

$$
S t V_{i}=\sum_{n=1}^{N} \frac{S t R_{i n}-S t C_{i n}}{\left(1+d_{i}\right)^{n}}=\sum_{n=1}^{N} \frac{\sum_{i=1}^{L} \vec{X}_{i l} r_{i l}-\sum_{k=1}^{K} \bar{X}_{i k} p_{i k}}{\left(1+d_{i}\right)^{n}}, i \in 1 ; M
$$

where $\mathbf{S t R}_{\mathbf{i n}}$ - value of the resources received; $\mathbf{S t C}$ in - value of resources transferred; di - discount rate; $\vec{X}_{i l}$ - natural volume of the resource 1 received from the enterprise; $\mathbf{r}_{i l}-$ value (profitability) of using the resource $1 ; \overline{\boldsymbol{X}}_{\boldsymbol{i} \boldsymbol{k}}$ - natural volume of the resource $\mathrm{k}$, transferred to the enterprise; $\mathbf{p}_{\mathbf{i k}}$ - value (price) of the resource for the stakeholder $\mathrm{i} ; \mathbf{M}-$ number of stakeholders of the enterprise.

Thus, the mechanism of the formation and assessment of the company's values $(\mathbf{V})$ and its stakeholders $(\mathbf{S t V})$, the maximization of which is the target functions of the parties, can be illustrated as follows:

$$
\begin{gathered}
V=\sum_{i=1}^{M} V_{i}=\sum_{i=1}^{M}\left(\sum_{n=1}^{N} \frac{R_{i n}-C_{i n}}{\left(1+d_{0}\right)^{n}}\right) \\
S t V=\sum_{i=1}^{M} S t V_{i}=\sum_{i=1}^{M}\left(\sum_{n=1}^{N} \frac{S t R_{i n}-S t C_{i n}}{\left(1+d_{i}\right)^{n}}\right)
\end{gathered}
$$

Companies must be provided with the resources to create value for each stakeholder. However, the maximization of stakeholder utility functions that express stakeholder preferences for certain types of value is subject to different conditions and limitations.

It therefore seems advisable to focus on the possibility of achieving some optimal balance of interests between the parties involved, equivalent to the maximum possible stakeholders' value, provided that no harm is done to each business participant:

$$
\begin{aligned}
& f_{0}\left(x_{0}\right) \rightarrow \max \Leftrightarrow \sum_{i=1}^{M} f_{i}\left(x_{i}\right) \rightarrow \max , \\
& D\left(x_{0}, x_{i}\right):\left\{0 \leq x_{0} \leq X_{0} ; 0 \leq x_{i} \leq X_{i} ; f_{i}\left(x_{i}\right) \geq 0\right\}
\end{aligned}
$$


If a balance of stakeholder interests is not found, this, given resource constraints in the medium term, will lead to attempts to either restore the balance or sever the relationship. Therefore, the management of the firm should maintain a resource balance in order to build mutually beneficial cooperation with interested parties.

In addition, managers need to pay attention not only to the absolute amounts of benefits generated for stakeholders, but also to compare them with other options available to them, and vice versa:

$$
\begin{aligned}
& f_{0}\left(x_{0}\right) \rightarrow \max \Leftrightarrow \sum_{i=1}^{M} f_{i}\left(x_{i}\right) \rightarrow \max , \\
& D\left(x_{0}, x_{i}\right):\left\{0 \leq x_{0} \leq X_{0} ; 0 \leq x_{i} \leq X_{i} ; \Delta\left(V_{i}\right) \geq 0 ; \Delta\left(S t V_{i}\right) \geq 0\right\}
\end{aligned}
$$

Where $\Delta\left(\mathbf{V}_{\mathbf{i}}\right)$ - company's rent; $\Delta\left(\mathbf{S t} \mathbf{V}_{\mathbf{i}}\right)$ - rent of stakeholder i.

Considering the fundamental impossibility of finding perfect maximizing techniques, it is advisable to consider the continuous increase of its value as the main strategic goal of the company, achieved through the gradual improvement of relationships with stakeholders and satisfaction of their interests.

Management of a firm in the financial interests of owners or shareholders is also important for creating value for all other stakeholders. It should be noted, however, that the concept of business value maximization does not imply that non-financial values, such as social and environmental aspects, are less important for creating value. Instead, these values are included in the financial value, taking into account their impact on the profitability of the firm.

Thus, the relationships described above form a model series, which fairly correctly reflects the relationship between the company and the stakeholders in terms of the creation of their values and therefore can be used further to develop practical tools for the approach to value management.

The particularity of the proposed CTV makes it possible to give a specific technological content to the approach to the company's value management: to formulate principles to ensure the achievement of management objectives, to determine the most appropriate actions of managers, to select and apply appropriate methods and tools.

For example, the key principles on which management should be based in the concept of CTV are:

- A broad interpretation of value. Values in business are so diverse that efforts to reduce this plurality of values to one common metric or measurement standard are unrealistic goals that ultimately reduce the total value created by firms.

- The need to take into account objective and subjective factors relevant to different economic agents.

- Improving the management process information field by researching stakeholder values.

- Development of a disclosure system that meets the interests of economic agents and ensures the required level of trust between them.

- Continuous monitoring of the overlapping values of stakeholders in order to find common interests and benefits as a basis for continuous cooperation. This would avoid the main networking problem of the perception that costs and benefits are not distributed equitably across the network.

These principles can be put into practice by applying the developed company value management algorithm based on the coordinated interaction of stakeholders, showing the sequence of the following interrelated steps:

1. Identification of stakeholders. As many external stakeholders as possible need to be identified and described. 
2. Analysis and identification of the most important external relations for the company. Ranking of stakeholders according to their importance for the development of the company's promising economic activities.

3. Determination of possible uses of the organization's resources in terms of performance, stakeholder satisfaction, trust building, knowledge creation, etc.

4. Analysis of the volume and structure of the organization's resources from the point of view of developing interaction with the priority stakeholders and increasing the total value of the company.

5. Mobilization of the company's internal reserves to increase the resource volume and improve the resource structure.

Thus, it can be concluded that the completion of all stages of the enterprise value management process provides opportunities for the necessary analysis and monitoring of essential indicators related to the external environment of the enterprise. It becomes possible to make specific management decisions aimed at maximizing the use of all stakeholder resources and, as a result, increasing the company's value.

\section{Conclusions}

1. The traditional model of corporate governance organization aimed at maximizing the income of owners does not reflect the critical transformations that have occurred in business in recent years: industrial revolution 4.0, transition to high information technology, digitalization and deep cooperation based on global value chains.

2. An adequate theoretical concept capable of providing the necessary improvement of corporate governance is the concept of the total value of stakeholders, redefining the value of the company in a broad context - as a resource, created by all stakeholders and business participants.

3. The proposed concept of total value, as opposed to the classical theory of stakeholders, considers the value of a company to be the total wealth of the organization and the sum of the value of all stakeholders, which together contribute to the overall public welfare of the established business ecosystem.

4. Thus, the concept of total value highlights the objective relationships that exist within the stakeholder network and that support its efficient functioning, thereby eliminating the contradiction between the increase in the company's value and the satisfaction of the interests of its stakeholders, since it unites them in the common task of maximizing the social welfare.

5. The process of corporate governance, in the light of the concept of total value, is based on a broad interpretation of the business objective and takes into account the total resource of the company's value growth, namely: all value flows, generated directly or indirectly by stakeholders and their productive interactions.

6. The practical lesson to be drawn from this concept is the objective need for continuous monitoring and analysis of stakeholders in order to provide information support of the management process, focus on the future, long-term engagement and trust of the parties, as well as the willingness to provide the most favorable conditions for all stakeholders in realizing their interests and achieving the stated business goals.

\section{References}

1. R. H. Coase, The nature of the firm. Economica,4, 386 (1937)

2. R.E. Freeman, Strategic Management: A Stakeholder Approach (1984)

3. T. Donaldson, L.E. Preston, Academy of Management Review, 20(1), 65 (1995) 
4. J.E. Post, L.E. Preston, S. Sashs, Redefining the Corporation: Stakeholder Management and Organizational Wealth (2002)

5. R.E. Freeman, Business Ethics Quarterly, 4, 409 (1994)

6. M.C. Jensen, Journal of Applied Corporate Finance, 14(3), 8 (2001)

7. F. Figge, S. Schaltegger, What Is Stakeholder Value? Developing a Catchphrase into Benchmarking Tool (2000)

8. R. K. Mitchell, G. R. Weaver, B. R. Agle, A. D. Bailey, J. Carlson, Academy of Management Review, 41(2), 252 (2016)

9. M.R. Kramer, M.W. Pfitzer, Harvard Business Review, 94(10), 80 (2016)

10. F. Bridoux, J. Stoelhorst, Strategic Management Journal, 35, 107 (2014)

11. C. Tantalo, R. L. Priem, StrategicManagement Journal, 37, 314 (2016) 